Bull. Fac. Agric., Cairo Univ., 71: 25-36 (2020).

\title{
A COMPARATIVE STUDY OF THE COSTS OF RAISING AND DESALINATING WELL WATER IN EGYPT USING DIFFERENT ENERGY FORMS
}

(Received: 2.6.2020)

\author{
By \\ Roqaya H. Gabr and Asmaa M. Taha \\ Department of Agricultural Economics , Faculty of Agriculture, Zagazig University,Egypt
}

\begin{abstract}
Groundwater plays an important role in providing Egypt with a portion of its water needs, as it comes third after the Nile River water and reused agricultural wastewater. The present study aimed to calculate the cost of raising a cubic meter of well water according to different desalination, and energy systems (solar - electrical - diesel), as well as calculating the cost of desalination of a cubic meters of well water. To achieve these objectives of the current study, several economic indicators were used, the most important of which were: the total cost per hour of operation, and the cost of lifting per cubic meter of well water subject to study. The study also estimated the cost of desalination of well water needed for human and animal use. The most important results of the study could be summarized as follow: the least costs of pumps were those of the solar energy pumps, where the cost of lifting amounted to about 0.35 pounds / hour, followed by electric pumps, where the cost of lifting amounted to about 0.80 pounds / hour, and by diesel pumps, where the cost of lifting amounted to 2.15 pounds / hour, assuming the existence of support. It was also clear that the processing units that operate with a production capacity of 20 thousand cubic meters per day are more efficient than the processing units that operate with a production capacity of 10 thousand cubic meters per day. Where the desalination cost a treated per unit of 20 thousand cobic meters perday was 0.76 L.E.L $\backslash \mathrm{m}^{3}$, while for processing units that have a production capacity of 10,000 cubic meters per day, the cost of desalination is about 1.27 pounds / cubic meters.
\end{abstract}

Key words: water, wells, cost, lifting, desalination.

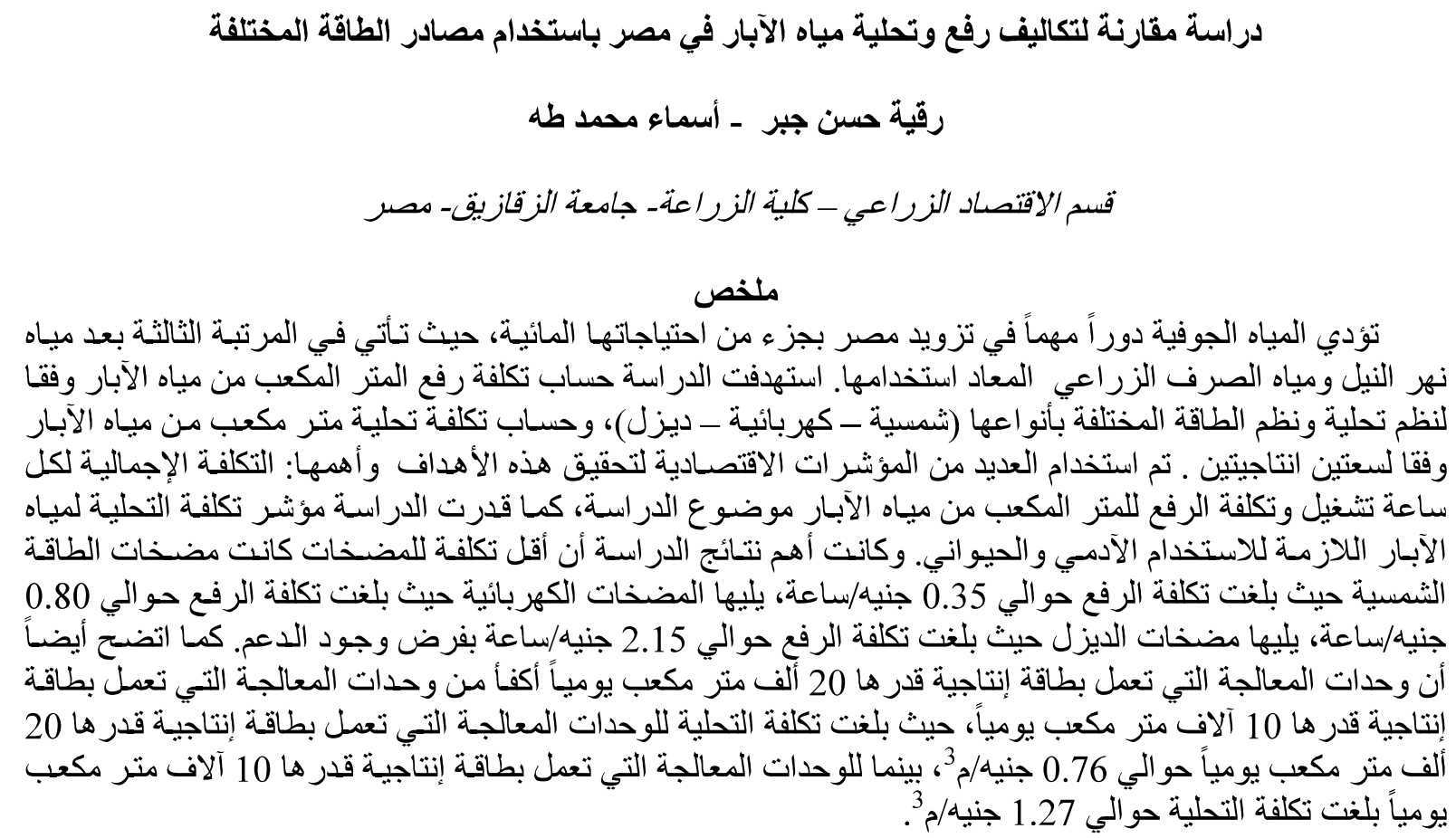


يقلل من مصـاريف التشـغيل. و أيضـا تعمل طلمبـات الطاقـة

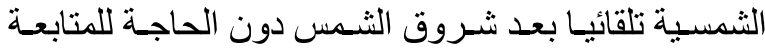

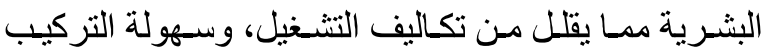

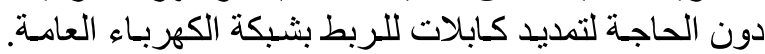

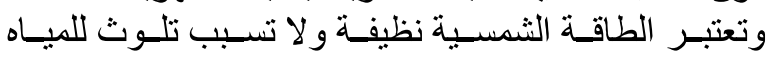

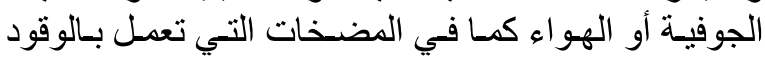

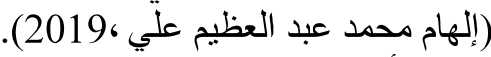

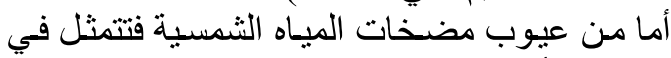

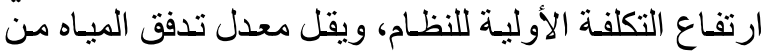

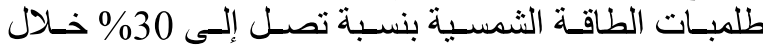

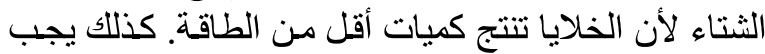

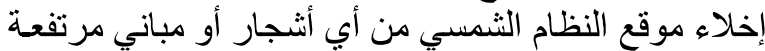

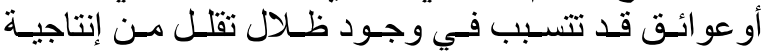

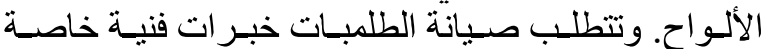

(النصر للطاقة الثمسية ،2019).

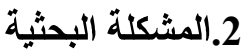

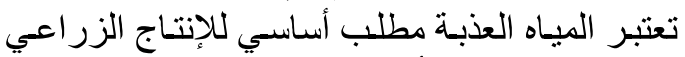

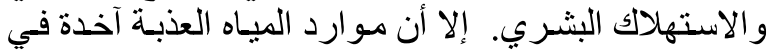

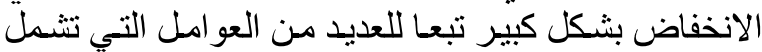

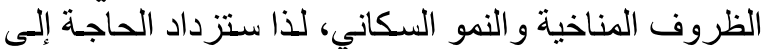

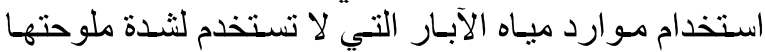

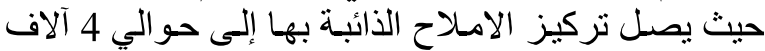

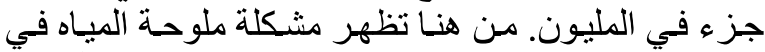

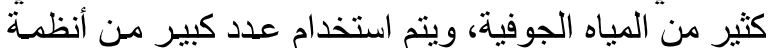

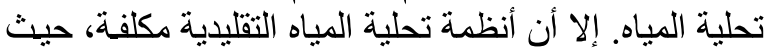

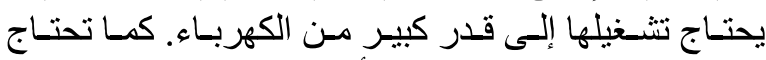

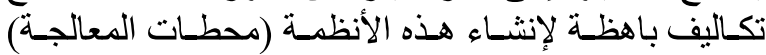

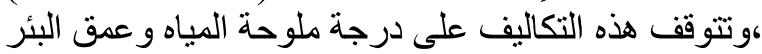
وتصرف البئر ونوع التكنولوجيا المستخدمة.

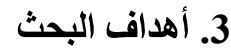

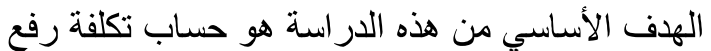

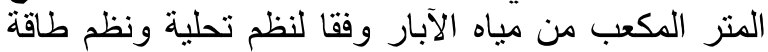

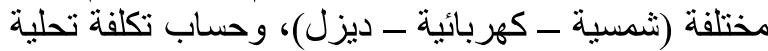
متر مكعب من مياه الآبار. كذللك المقارنة بينها وفية وفقا لسعات إنتاجية مختلفة ووفقا لنظم تشغيل مختلفة في عينة الدار استة،

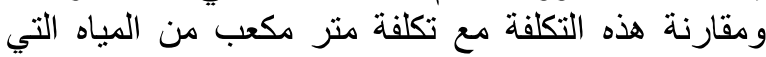

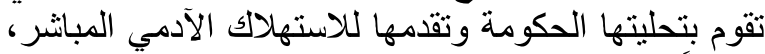

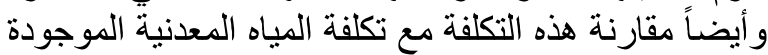

$$
\text { في الأسواق المصرية. }
$$

\section{4. الطريقة البحثية ومصادر البيانات}

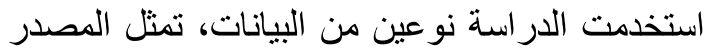

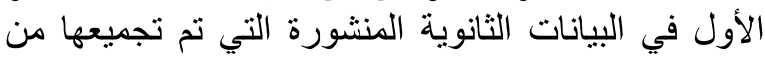

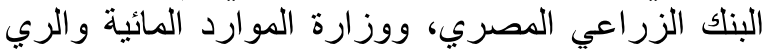

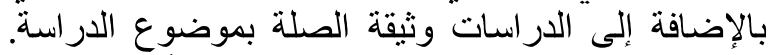
وتمثل المصدر الثاني في بيانات ميدانية أولية خاصية الإنة الإنة بتكاليف حفر و إنثاء وتثغيل الآبار الأرتوازية، وتكاليف

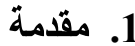

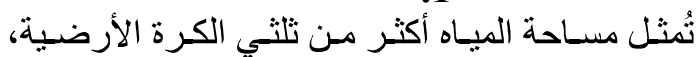
ولكن 3\% فقط من المياه عذبة و97 \% من من الميـاه مالحسة. و

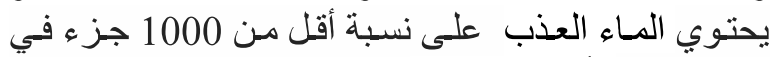

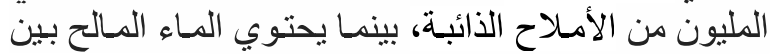

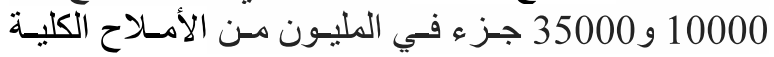

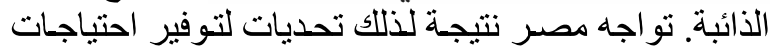

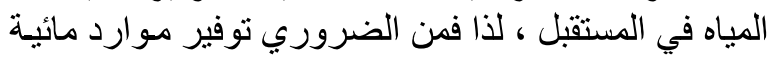

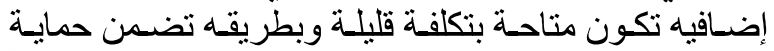

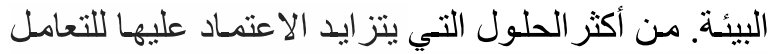

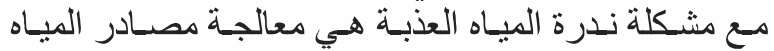
المالحة، من خلال عملية تعرف باسم تحلية الميلة المياه.

تحلية المياه هي عملية تحويل المياه المالحة إلى مياه

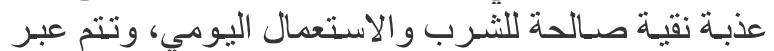

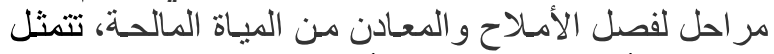

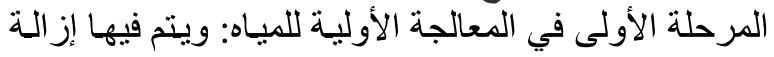

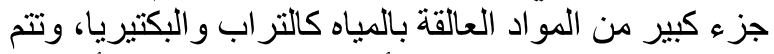

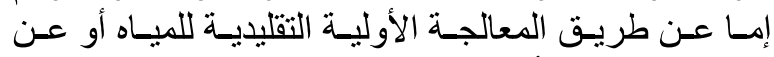

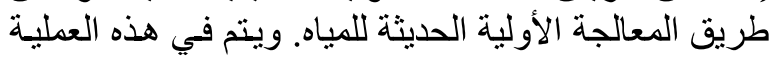

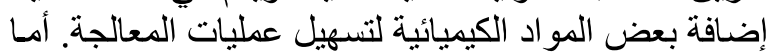

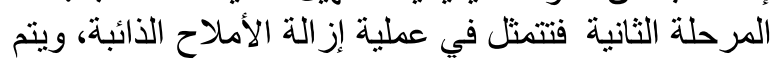

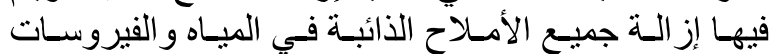

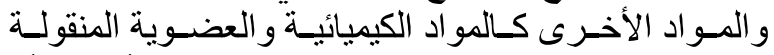

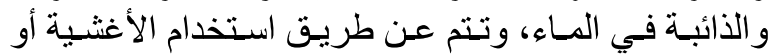

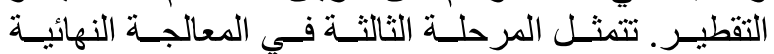

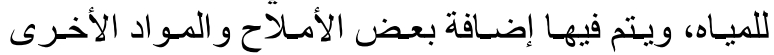

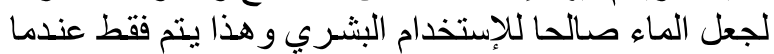

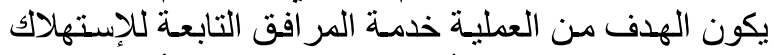

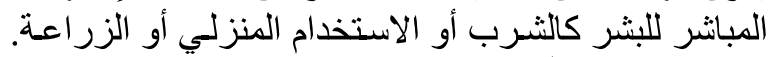

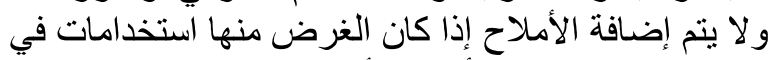

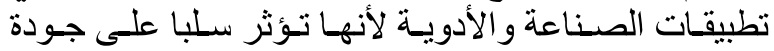
المنتج (Wayback Machine, 2017).

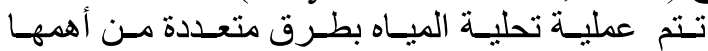

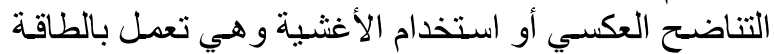

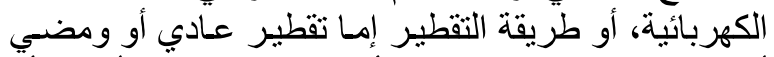

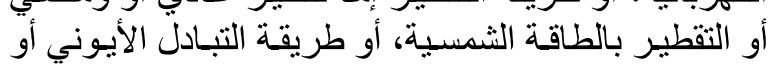

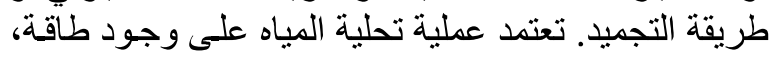

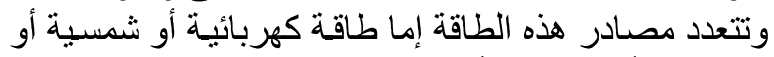

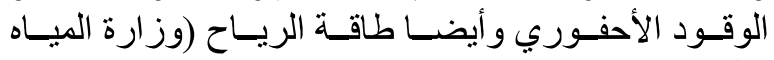
و الكهرباء ،2017).

مـن التقنيـات المسـتخدمة في تحليـة الميـاه اسـتخدام مضخات المياه الثمسية والتي تعتمد على الطاقة الثمسية الثية الثياه

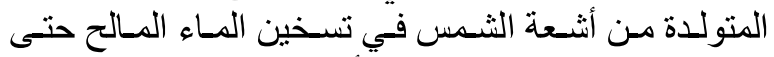

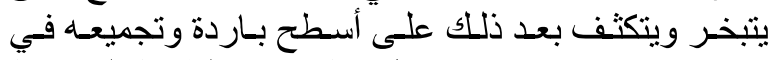

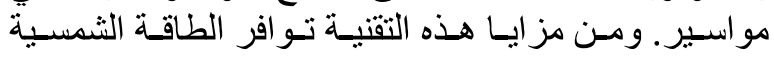

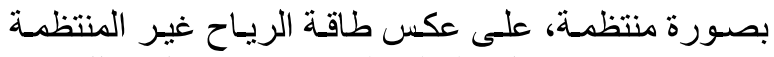

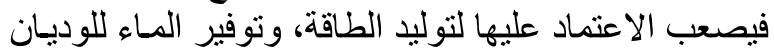

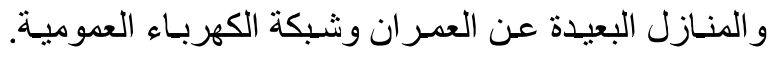

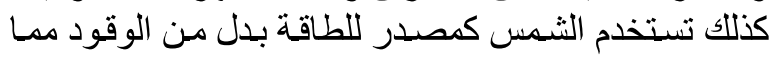


1.1.5 تكلقة الرفع باستخدام مضخات الكهرباء

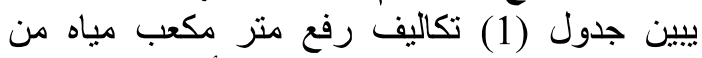
الآبار باستخدام مضخات كهربائية وفقا لأسعار الكهرباء، ويتضح أن إجمالي التكاليف الثابتة بلغت حوالية لألي 12.93

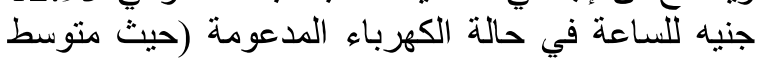

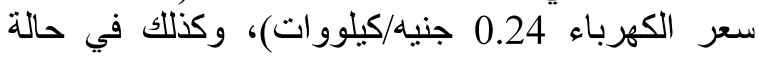

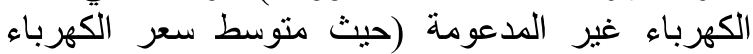

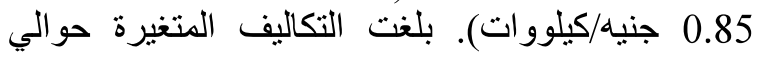
112.794جنيه للساعة في حالة الكهرباء الكياء المدعومة

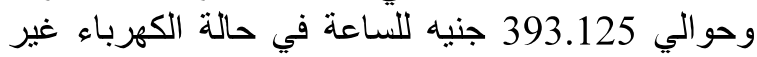
المدعومة. من ثم بلغت تكلفة رفع المترمكعب من من مئ مياه

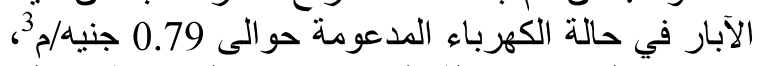

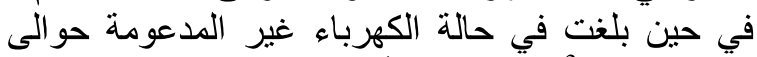

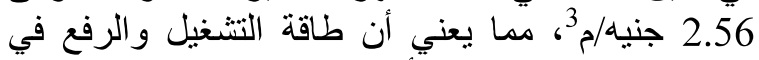

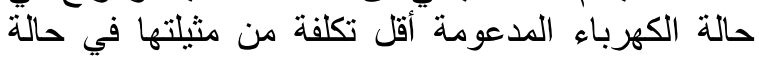

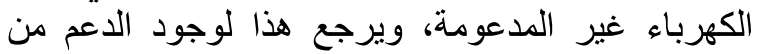
عدمه. بالتالي توفير دعم الكهرباء لمستخدمي الآبار

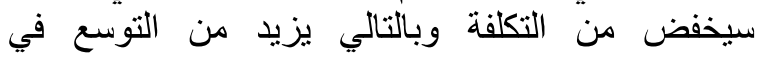

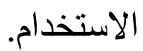

تم حساب هذه التكاليف بناء على سعر الفائدة (10.5 \%)، وكذلك على متوسط مدة التشغيل اليومي 10 ساعات، الئل

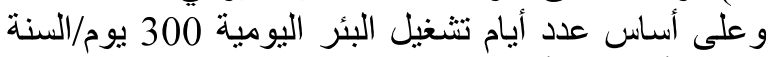

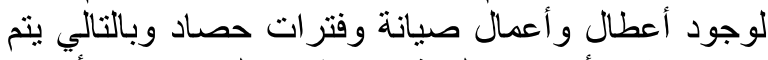

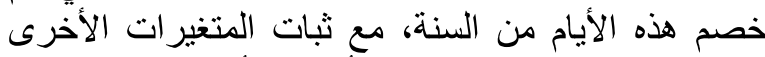

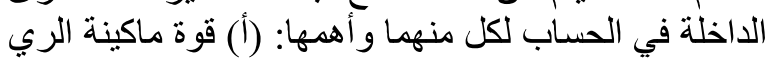

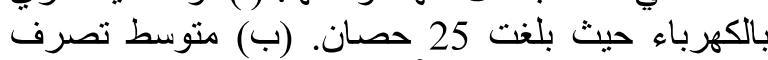

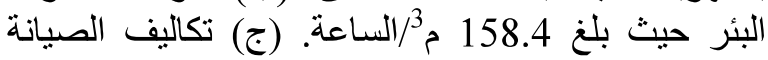

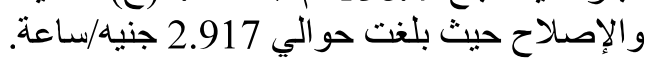

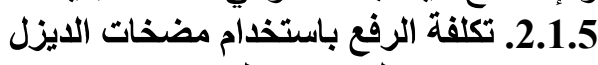

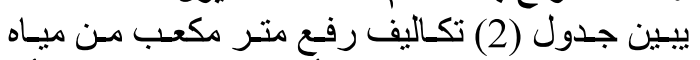

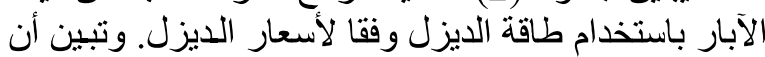

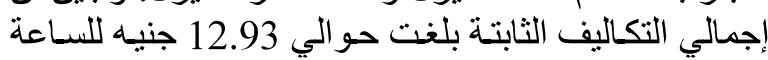

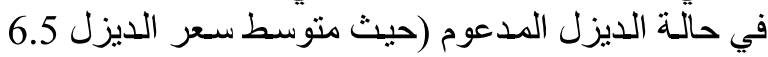

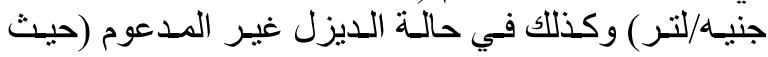

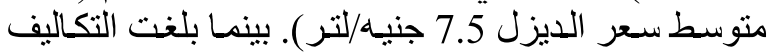

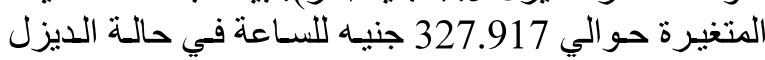

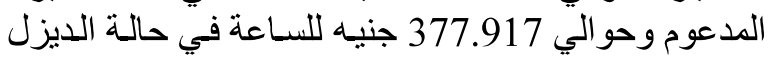

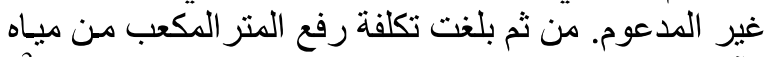

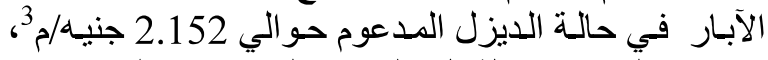

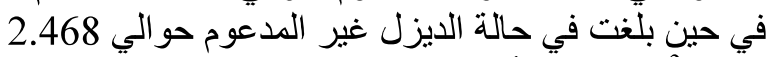

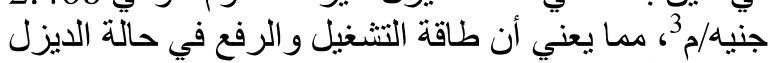

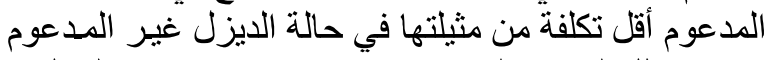

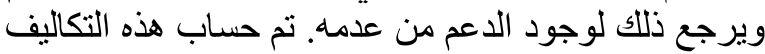

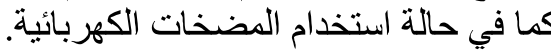

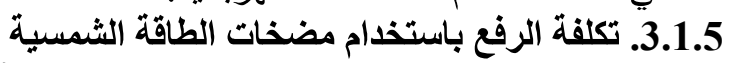
يبين جدول (3) تكاليف رفع متر مكعب مئي مياه من الآبار

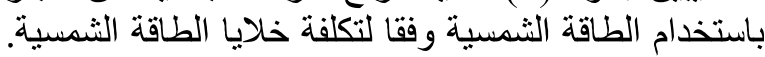

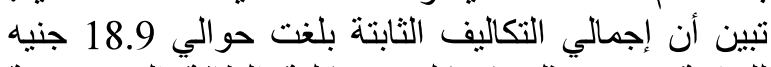

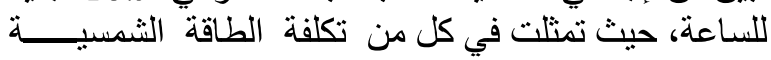

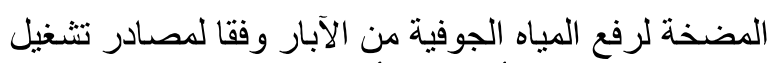

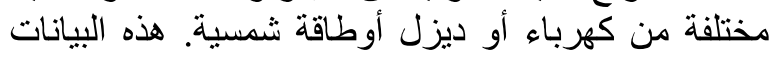

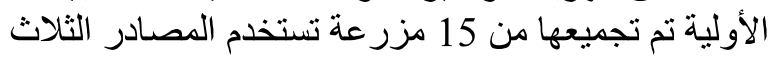

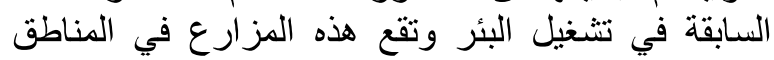

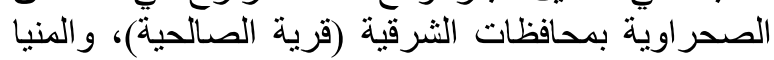

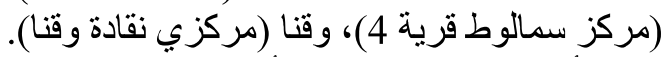

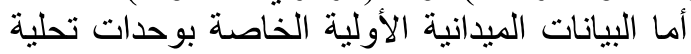

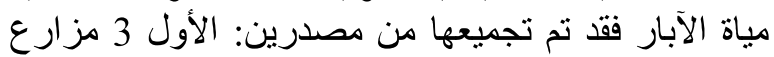

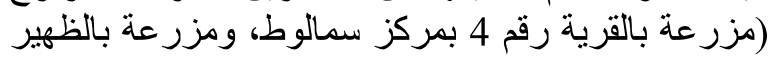

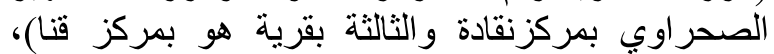

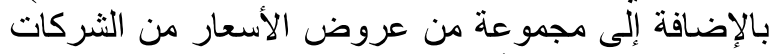

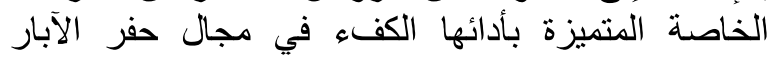

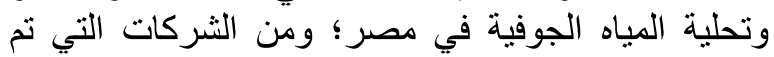

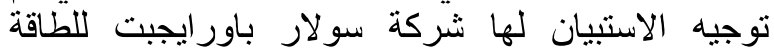

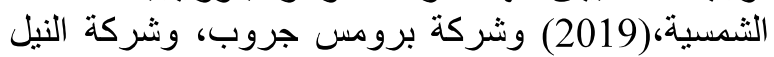

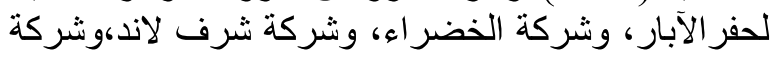

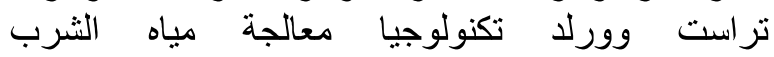

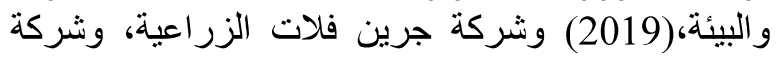

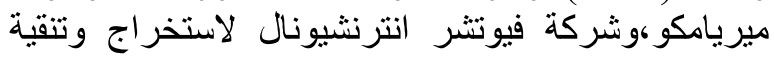

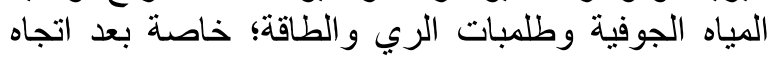
وزارة الري والموارد المائيةٌ في العقد الأخير إلى إلى إسناد الفياه

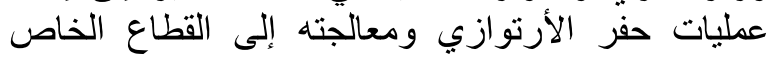

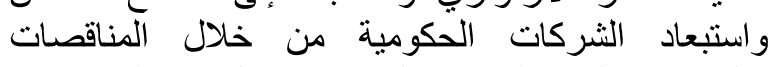
والمز ايدات التي تعلن عنها الحكومة في الجية الجر ائد الرسمية.

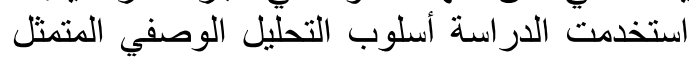

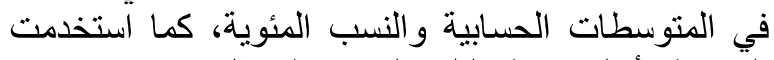

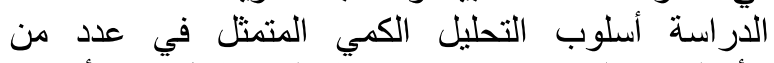

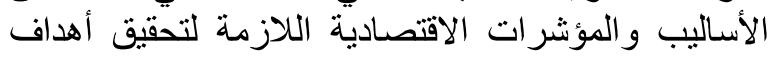

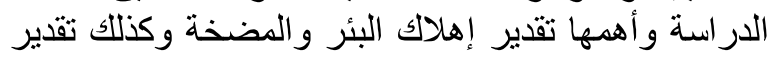

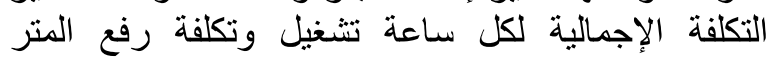

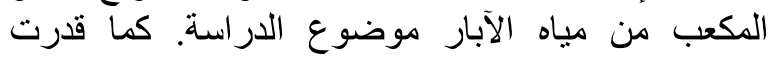

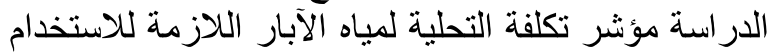
الآدمي و الحيو اني والاستخدامات المنزلية لئية الألية

\section{5. 5 النتائج ومناقشتها

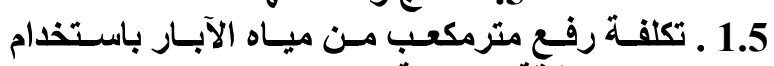

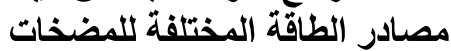

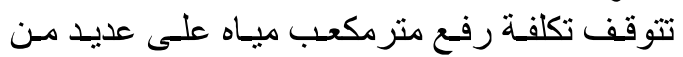

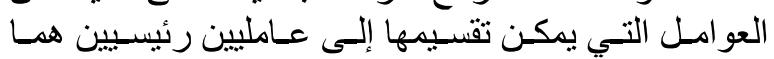

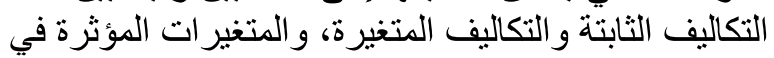

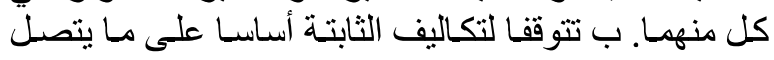

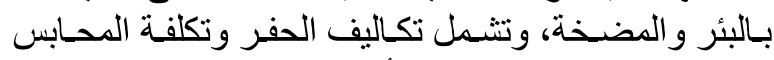

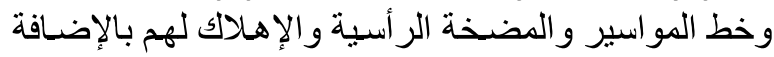

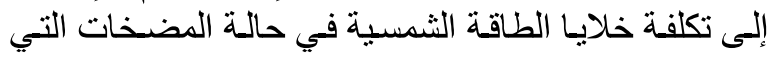

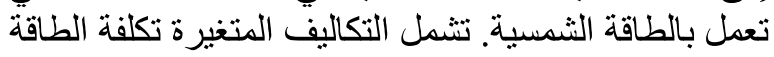

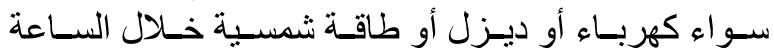
وتكاليف الإصلاح و الصيانة. 


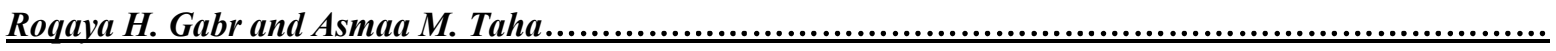

جدول (1): تكاليف رفع متر مكعب مياه من الآبار باستخدام مضخات كهربائية وفقا لأسعار الطاقة.

\begin{tabular}{|c|c|c|c|}
\hline كهرباء غير مدعومة & كهرباء مدعومة & 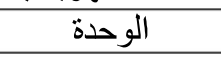 & البنود \\
\hline & & & أو لا: التكاليف الثابتة \\
\hline & & & 1- ت تكاليف إنشاء البئز \\
\hline 100 & 100 & متز & عمق البئر \\
\hline 450 & 450 & جنيه /متر & تكاليف الحفر لكل متر عمق \\
\hline 45000 & 45000 & جنيه & إجمالى تكلفة الحفر (1) \\
\hline 25 & 25 & سنة & متوسط عمر البئر الإنتاجى بالسنة \\
\hline 300 & 300 & يوم & متوسط عدد أيام تتغيل البئر سنويا \\
\hline 10 & 10 & ساعة & متوسط عدد ساعات التتشغيل اليومي \\
\hline 75000 & 75000 & ساعة & العمر الإنتاجى للبئر بالساعة(2) \\
\hline \multirow[t]{2}{*}{0.6} & 0.6 & جنيه /ساعة & إهلاك النبئز بالساعة(3) \\
\hline & & & 2- 2 ت تكاليف المضخة \\
\hline 157500 & 157500 & جنيه & تكلفة المحبس وخط المو اسير و الطلمبة الغاطسة (25 حصان) \\
\hline 10 & 10 & سنة & متوسط عمر الإنتاجي للمضخة \\
\hline 300 & 300 & يوم & متوسط عدد أيام تشغيل المضخة سنويا \\
\hline 10 & 10 & ساعة - كاعة & متوسط عدد ساعات التشغيل اليومى للمضخة \\
\hline 30000 & 30000 & ساعة & العمر الإنتاجي للمضخة بالساعة(4) \\
\hline 5.25 & 5.25 & جنيه /ساعة & إهلاك المضخة ومشتملاتها بالساعة(5) \\
\hline 5.85 & 5.85 & جنيه /ساعة & إجمالى الإهلاك للبئز والمضخة بمشتملاتها \\
\hline 0.105 & 0.105 & $\%$ & 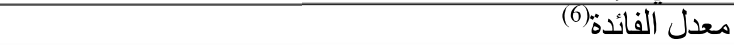 \\
\hline 4725 & 4725 & جنيه /سنة & الفائدة على رأس المال المستثمر في البئر (7) \\
\hline 16537.5 & 16537.5 & جنيه /سنة & الفائدة على رأس المال المستثر في الدضخة ومشتصلاتها(8) \\
\hline 21262.5 & 21262.5 & جنيه /سنة & إجمالي الفائدة على رأس المال المستقِمر (9) \\
\hline 7.088 & 7.088 & جنيه /ساعة & إجمالي الفائدة على رأس المال المستثر \\
\hline \multirow[t]{2}{*}{12.938} & 12.938 & جنيه /ساعة & إجمالي التكاليف الثابتة للّساعة(10) \\
\hline & & & ثانيا: التكاليف المتغيرة \\
\hline 25 & 25 & حصLان ميكانيكي & طاقة المضخة \\
\hline 18.38 & 18.38 & كيلووات/ساعة & متوسط استهلاك الكهرباء \\
\hline 0.85 & 0.24 & جنيه/ كيلووات & منوسط سعر الكهرباء \\
\hline 390.63 & 110.29 & جنيه /ساعة & تكاليف الكهرباء(11) \\
\hline 2.5 & 2.5 & جنيه /ساعة & الصيانة و الإصلاحات(12) \\
\hline 393.125 & 112.794 & جنيه /ساعة & إجمالي التكاليف المتغيرة بالساعة(13) \\
\hline \multirow[t]{2}{*}{406.068} & 125.738 & جنيه /ساعة & إجمالي التكاليف الكلية بالساعة \\
\hline & & & الثالثا: تكاليف المتر المكعب \\
\hline 158 & 158 & متر مكعب/ساعة & متوسط تصرف البئر في الساعة(14) \\
\hline 2.56 & 0.79 & جنيه /متر مكعب & تكاليف رفع متر مكعب(15) \\
\hline
\end{tabular}

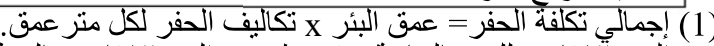

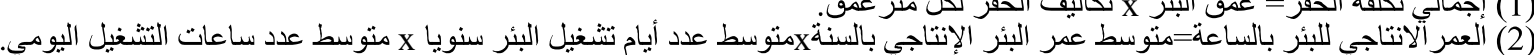

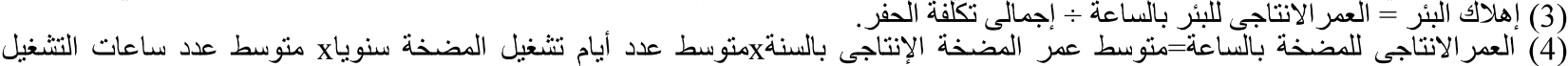

(5) إهلاككي" المضخة = تكلفة المحبس وخط المو اسير و الطلمبة الغاطسة ؛ العمر الإنتاجى للمضخة بالساعة.

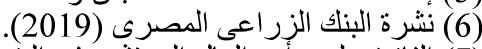

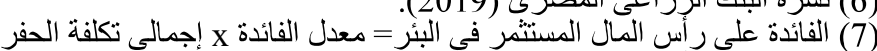

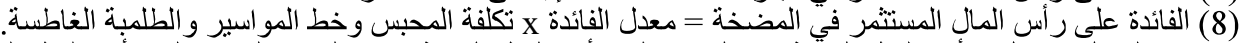

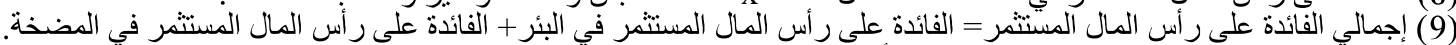

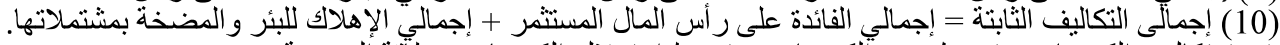

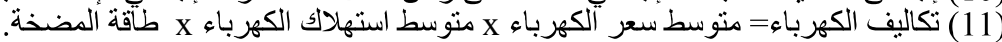

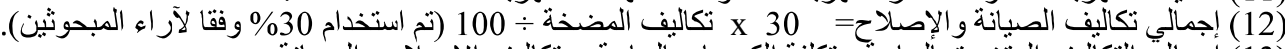

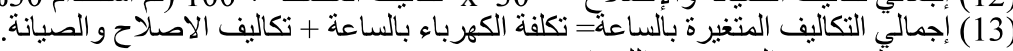

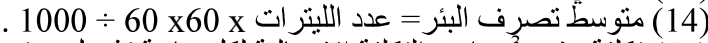

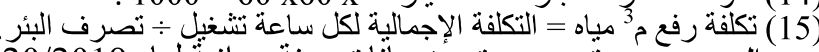

المصدر: جمعت و حسبت من بيانات عينة ميدانيةً لعام 2020/2019. 
جدول (2): تكاليف رفع متر مكعب مياه من الآبار باستخدام مضخات ديزل وفقا لأسعار الطاقة.

\begin{tabular}{|c|c|c|c|}
\hline ديزل سعر حر & ديزل مدعوم & 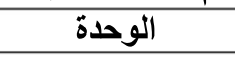 & البنود \\
\hline & & & أو الا: التكاليف الثابتة \\
\hline & & & 1- تكاليف انشاء البئر \\
\hline 100 & 100 & متز & عمق البئر \\
\hline 450 & 450 & جنيه/متر & تكاليف الحفر لكل متر عمق \\
\hline 45000 & 45000 & جنيه & إجمالى تكلفة الحفر \\
\hline 25 & 25 & سنة & متوسط عر البئر الإنتاجى بالسنة \\
\hline 300 & 300 & يو م & متوسط عدد أيام تشغيل البئر سنويا \\
\hline 10 & 10 & ساعة - ( - كاعة & متوسط عدد ساعات التتنغيل اليومي \\
\hline 75000 & 75000 & ساعة & العمر الإنتاجى للبئر بالساعة \\
\hline \multirow[t]{2}{*}{0.6} & 0.6 & جنيه/ساعة & إهلاك النبئر بالساعة \\
\hline & & & 2- تكاليف المضخة \\
\hline 157500 & 157500 & جنيه & تكلفة المحبس وخط المو اسير و الطلمبة الغاطسة (25 حصان) \\
\hline 10 & 10 & سنة & متوسط عمر الإنتاجي للمضخة \\
\hline 300 & 300 & يوم & متوسط عدد أيام تشغيلّل المضخة سنويا \\
\hline 10 & 10 & ساعة - كاعة & متوسط عدد ساعات التشغيل اليومى للمضخة \\
\hline 30000 & 30000 & ساعة & العمر الإنتاجى للمضخة بالساعة \\
\hline 5.25 & 5.25 & جنيه/ساعة & إهلاك المضخة ومشتملاتها بالساعة \\
\hline 5.85 & 5.85 & جنيه/ساعة & إجمالي الإهلاك للبئز و المضخة بمشتملاتها \\
\hline 0.105 & 0.105 & $\%$ & معدل آلفائدة \\
\hline 4725 & 4725 & جنيه/سنة & الفائدة على رأس المال المستثمر في البئر \\
\hline 16537.5 & 16537.5 & جنيه/سنة & الفائدة على رأس المال المستثر في المضخة ومشتملاتها \\
\hline 21262.5 & 21262.5 & جنيه /سنة & إجمالي الفائدة على رأس المال المستَتُمر \\
\hline 7.088 & 7.088 & جنيه /ساعة & إجمالي الفائدة على رأس المال المستثر \\
\hline \multirow[t]{2}{*}{12.938} & 12.938 & جنيه /ساعة & إجمالي التكاليف الثابتة للساعة \\
\hline & & & |ثانيا: التكاليف المتغيرة \\
\hline 25 & 25 & حصان ميكانيكي & طاقة المضخة \\
\hline 2 & 2 & لتر/ ساعة & متوسط استهلاك الديزل \\
\hline 7.5 & 6.5 & جنيه / لتر & متوسط سعر الديزل \\
\hline 375 & 325 & جنيه/ ساعة & تكاليف الديزل \\
\hline 2.917 & 2.917 & جنيه / ساعة & الصيانة و الإصلاحات" \\
\hline 377.917 & 327.917 & جنيه / ساعة & إجمالي التكاليف المتغيرة بالساعة \\
\hline \multirow[t]{2}{*}{390.854} & 340.854 & جنيه / ساعة & إجمالي التكاليف الكلية بالساعة \\
\hline & & & إلثا: تكاليف المتر المكعب \\
\hline 158.4 & 158.4 & متر مكعب/ ساعة & متوسط تصرف البئر في الساعة \\
\hline 2.468 & 2.152 & جنيه / متر مكعب & تكاليف رفع متر مكعب \\
\hline
\end{tabular}

* إجمالي تكاليف الصيانة والإصلاح= 35 x تكاليف المضخة ج 100 (تم استخدام 35 \% وفقا لآراء المبحوثين)

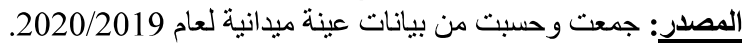

قيمتها حو الي 2.39 جنيه للساعة، وهي تمثل حوالي 35 ونة

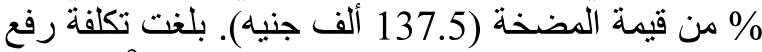

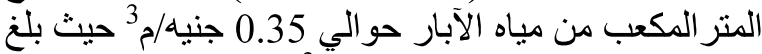

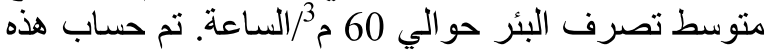

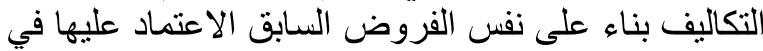

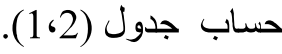

بلغت حو الي 137.5 ألف جنيه، و إجمالي الفائدة على رأس

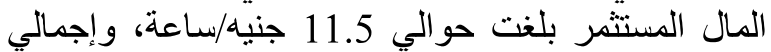

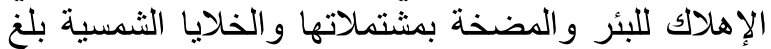
حوالي 7.35 جنيه/ساعة. أُما بالنسبة للتكاليف المتغيرة بلغت حوالي 2.39 جنيه للساعة، تمثلت في تكاليف الإصلاح والصنيف الصيانة بلغت 


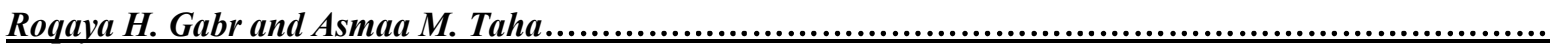

جدول (3): تكاليف رفع متر مكعب مياه من الآبار باستخدام مضخات تعمل بالطاقة الشمسية.

\begin{tabular}{|c|c|c|}
\hline القيمة - م القية & 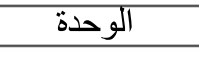 & 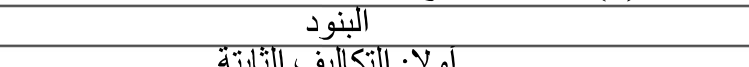 \\
\hline & & أولا: التكاليف الثابتة \\
\hline & & 1 1- ت تكاليف انشاء البئر \\
\hline 100 & 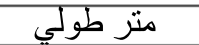 & 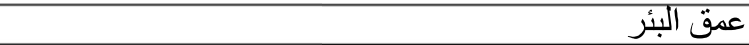 \\
\hline 25 & سنة & متوسط عمر البئر الإنتاجى بالسنة \\
\hline 300 & يوم & متوسط عدد أيام تثَغيل البئر سنويا \\
\hline 10 & ساعة & متوسط عدد ساعات التشغيل اليومي \\
\hline 75000 & ساعة & العمر الإنتاجى لللبئر بالساعة \\
\hline 450 & جنيه & تكاليف ألَحفر لكل متر عمق \\
\hline 45000 & جنيه & إجمالَى تكلفة الحفر \\
\hline 0.60 & جنيه & إهلاك البئر بالساعة \\
\hline & & 2 \\
\hline 147500 & جنيه & تكلفة الححبس وخط المواسير والطلمبة الغاطسة (16 حصان) \\
\hline 10 & سنة & متوسط عمر الإنتاجي للمضخة: \\
\hline 300 & يوم & متوسط عدد ايام تثنغيَّل المضخة سنويا \\
\hline 10 & ساعة & متوسط عدد ساعات التتُغيل اليومي للمضخة \\
\hline 30000 & 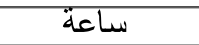 & العمر الإنتاجى للمضخة بالساعة \\
\hline 4.92 & جنيه / ساعة & إهلاك المضخة ومشتنملاتها بالساعة \\
\hline & & 3- ت تكاليف الطاقة الثمسية \\
\hline 137500 & جنيه & تكلفة خلايا الطاقة النمسية" ت \\
\hline 25 & سنة & متوسط العمر الإنتاجى بالسنة \\
\hline 300 & يوم & متوسط عدد أيام تثنغيل سنويا \\
\hline 10 & ساعة & متوسط عدد ساعات التتشغيل اليومي \\
\hline 75000 & ساعة & متوسط العمر الإنتاجى للخلايا بالسّاعة \\
\hline 1.83 & جنيه / ساعة & إهلاك الخلايا النُمسيةًة)(1) \\
\hline 7.35 & جنيه / ساعة & إجمالي الإهلاك للبئز و المضخة بمشتملاتها و الخلايا الثمسية:(2) \\
\hline$\% 10.5$ & $\%$ & معدل آلفائدة \\
\hline 4725 & جنيه & 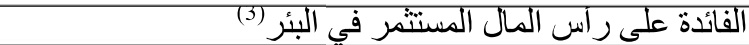 \\
\hline 15488 & جنيه & الفائدة على راس المال المستثمر في المضخة ومشتملاتها(4) \\
\hline 14438 & جنيه & الفائدة على راس المال المستخمر في الخلايا الثُمسية:(د) \\
\hline 34650 & جنيه & إجمالي الفائدة على راس المال المستختمر (b) \\
\hline 11.55 & جنيه / ساعة & إجمالي" الفائدة على راس المال المستخّر \\
\hline 18.90 & جنيه / ساعة & إجمالي التكاليف الثابتة للساعة \\
\hline & & إنانيا: التكاليف المتغيرة \\
\hline 2.39 & جنيه /ساعة & تكاليف الصيانة و الإصلاح35\% من قيمة المضخة \\
\hline 2.39 & جنيه /ساعة & إجمالي التكاليف المتغيرة \\
\hline 21.29 & جنيه / ساعة & ألتكلفة الإجمالية لكل ساعة تُشغيل(/) \\
\hline & & أثالتا: التكلفة لكل متر م ماء \\
\hline 60 & متر مكعب & تصرف البئز \\
\hline 0.35 & جنيه / متر مكعب & تكلفة الرفع للمتر المكعب من الماء \\
\hline
\end{tabular}

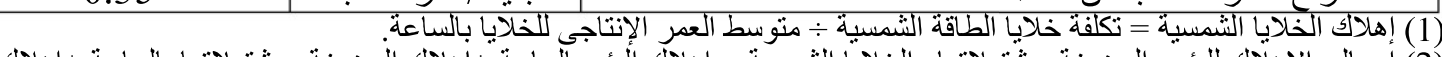

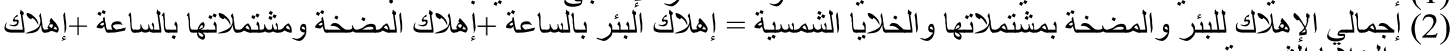
الخلإيا الثنمسية.

(3) الفائدة على رأس المال المستثر في البئر = معدل الفائدة * إجمالي تكلفة الحفر

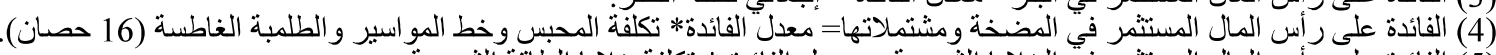

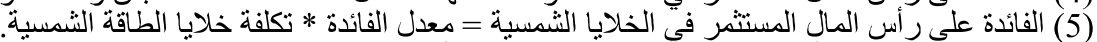

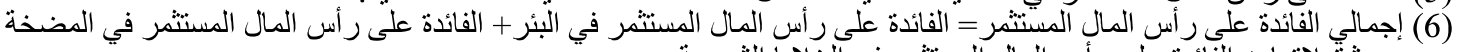

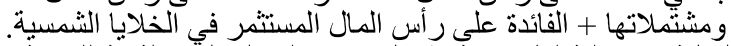

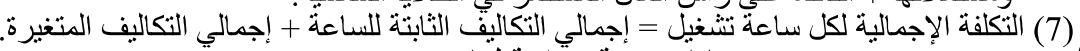
المصدر: جععت وحسبت من بيانات عينة ميدانية لُعام 2020/2019.

الكهربائية في حالة وجود دعم للكهرباء؛ بلغت التكاليف

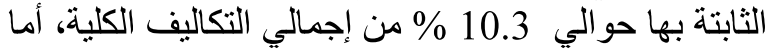

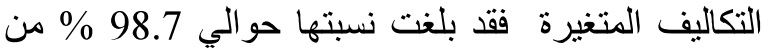

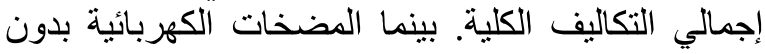
وجود دعم للكهرباء؛ بلغت التكاليف الثابتة حوالى 3.2 \% الكرباتية
2.5 تحليل مقارن لتكاليف رفع مترمكب مياه باستخدام المضخات المختلفة

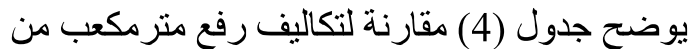

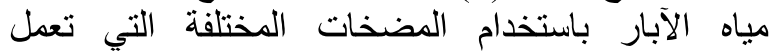
بالكهرباء والديزل والطاقة الثمسية. تبين أن المضخات التيات 
جدول (4): مقارنة تكاليف توزيع متر مكب مياه باستخدام المضخات المختلفة.

\begin{tabular}{|c|c|c|c|c|c|c|c|c|c|c|}
\hline \multicolumn{2}{|c|}{ مضخات بالطاقة } & \multicolumn{4}{|c|}{ مضخات ديزل } & \multicolumn{4}{|c|}{ مضخات بالكهرباء } & \multirow{3}{*}{ البنود } \\
\hline \multirow{2}{*}{$\%$} & \multirow{2}{*}{ جنيه/ساعة } & \multirow{2}{*}{$\%$} & بدون دعم & \multirow{2}{*}{$\%$} & وجود دعم & \multirow{2}{*}{$\%$} & \multirow{2}{*}{ جنيه/ساعة دعم } & \multirow{2}{*}{$\%$} & وجود دعم & \\
\hline & & & جنيه/ساعة & & جنيه/ساعة & & & & جنيه/ساعة & \\
\hline 88.77 & 18.9 & 3.31 & 12.94 & 3.8 & 12.94 & 3.19 & 12.94 & 10.29 & 12.94 & التكاليف الثثابتة \\
\hline 11.23 & 2.39 & 96.69 & 377.92 & 96.2 & 327.92 & 96.81 & 393.125 & 89.71 & 112.794 & التكتيرة \\
\hline 100 & 21.29 & 100 & 390.854 & 100 & 340.854 & 100 & 406.063 & 100 & 125.732 & التكالّف التكلية \\
\hline- & 0.35 & - & 2.47 & - & 2.15 & - & 2.56 & - & 0.79 & تكاليف رفع م³ \\
\hline
\end{tabular}

المصدر: حسبث من الجداول (1، 2، 3، 3) 3.

وقد اقتصرت الدراسة على نوعان من وحدات

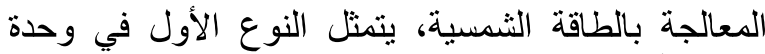

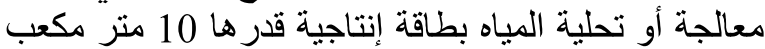

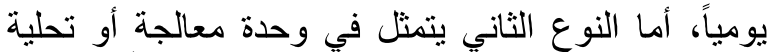

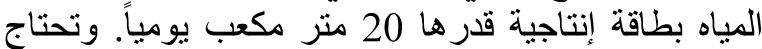

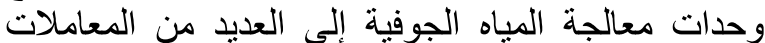
الفنية اللازمة لكي تعطي الطاقة الإنتاجية المستهدفة مشار الفيد الميار إليها بالملحق. 1.3.5 تقلير تكاليف معالجة أو تحلية المتر المكب من

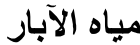

استخدمت الدراسة نوعين من الآبار المخصصة

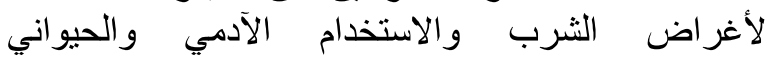
والاستخدامات المنزلية. يتمثل النوع الأول في الآبار التي

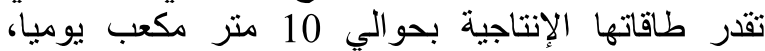

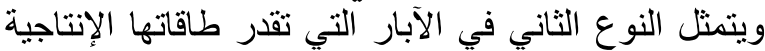
بحو الي 20 متر مكعب يو ئيا.

1.1.3.5 تقدير تكاليف معالجة أو تحلية المتر المكب المب من

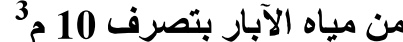

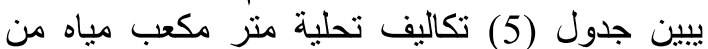

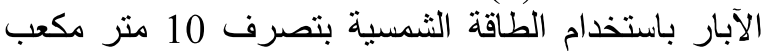

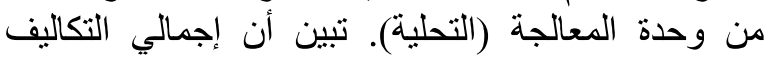

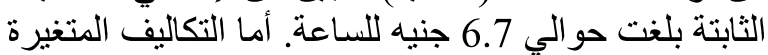
بلغت حوالي 6 جنيه للساعة، تمثلت في كل من من تكاليف الإصلاح والصيانة بلغت قيمتها حوالي 6 جنيه تلإنها للساعة. بلغت تكلفة تحلية المتر المكعب من مياه الآبار حوالي 1.27

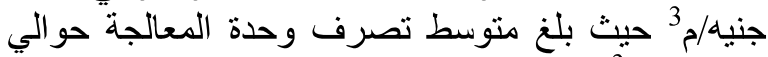

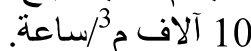

تم حساب هذه التكاليف بناءا على سعر الفائدة على التى الإقراض (10.5 \%)، وكذلك على متوسط مدة التشغيل

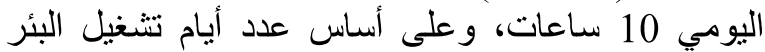

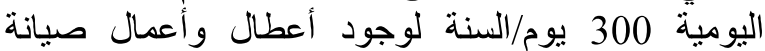
وفترات حصاد وبالتالي يتم خصم هذه الأيام من السنة.

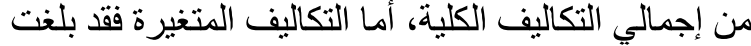
نسبتها حو الى 96.8 \% من إجمالي التكاليف الكلية.

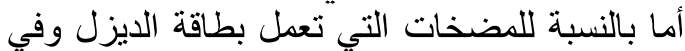

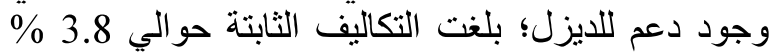

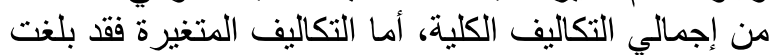
نسبتها حوالي 96.2 \% من إجمالي التكاليف الكلية. بينما

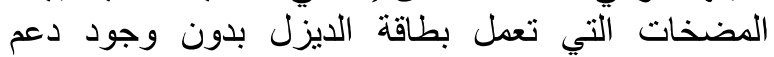
للايزل؛ بلغت آلتكاليف الثابتة حوالي 3.3 \% من من إجمالي التكاليف الكلية، أما التكاليف المتغيرة فقد بلغت نسبته حوالي 96.7 \% من إجمالي التكاليف الكلية.

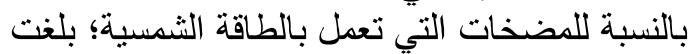
التكاليف الثابتة بها حوالي 88.77 \% من إلجمالي التكاليف

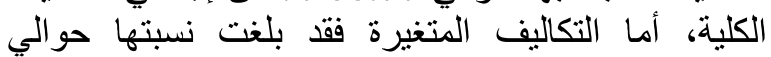
11.23 \% من إجمالي التكاليف الكلية. بمقارنة تكلفة الرفع باستخدام المضخات السابفة المابق

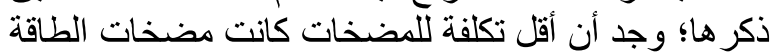
الثمسية حيث بلغت تكلفة الرفع حو الى الى 0.35 جنيه/ساعة، التهات يليها مضخات الديزل حيث بلغيت بكلت الرفع تكلفة الرفع حو الي 2.47

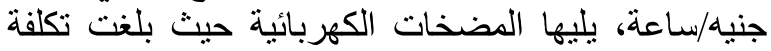
الرفع حو الي 2.56 جنيه/ ساعة الجة. 3.5 تكلقة معالجة أو تحلية المتر المكعب من مياه الآبار تعمل محطات تحلية مياه الآبار في مصلية مصر ملاه على الآلى

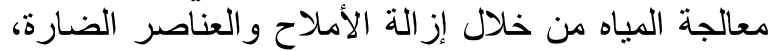

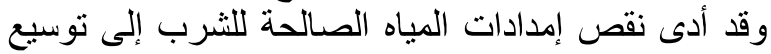

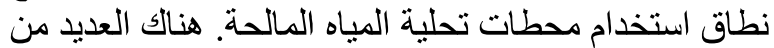

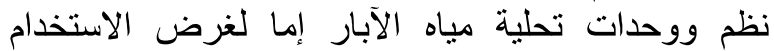

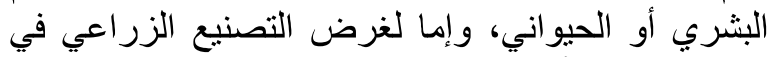

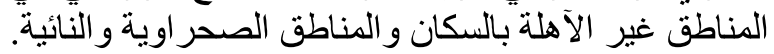

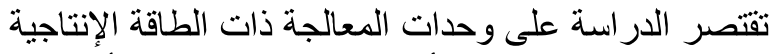

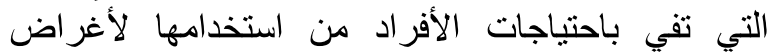

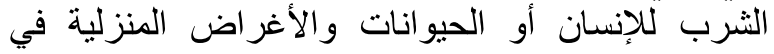

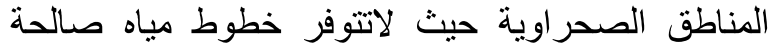
للثرب من قبل الدولة (معهد التخطيط القومي،2017). 
جدول (5): تكاليف تحلية أو معالجة متر مكعب من مياه الآبار بطاقة إنتاجية قدرها 10 متر مكعب يومياً.

\begin{tabular}{|c|c|c|}
\hline طاقة 10 م3 & الوحدة & البنود \\
\hline & & أولاً: التكاليف الثابتة \\
\hline 95000 & جنيه & تكلفة خلايا الطاقة الثمسية ومستلزماتها المختلفة \\
\hline 25 & سنة & متوسط العمر الإنتاجي للوحدة بالسنة \\
\hline 300 & يوم & متوسط عدد أيام التشغيل سنويا \\
\hline 10 & ساعة & متوسط عدد ساعات التشغيل اليومي \\
\hline 75000 & ساعة & العمر الإنتاجي للوحدة بالساعة \\
\hline 1.267 & جنيه /ساعة & متوسط إهلاك الخلايا الثمسية ومستلزماتها \\
\hline 44000 & جنيه & تكلفة إنشاء غرفة الوحدة \\
\hline 0.587 & جنيه /ساعة & إهلاك غرفة الوحدة \\
\hline 0.105 & $\%$ & معدل الفائدة \\
\hline 9975 & جنيه & الفائدة على رأس المال المستثمر في الخلايا الثمسية \\
\hline 3.325 & جنيه /ساعة & الفائدة على رأس المال المستثمر في الخلايا الثمسية بالساعة \\
\hline 4620 & جنيه & الفائدة على رأس المال المستثر في غرفة الوحدة \\
\hline 1.54 & جنيه /ساعة & الفائدة على رأس المال المستثر في غرفة الوحدة بالساعة \\
\hline \multirow[t]{2}{*}{6.718} & جنيه /ساعة & إجمالي التكاليف الثابتة للساعة \\
\hline & & أنانياً: التكاليف المتغيرة \\
\hline 18000 & جنيه & عقد صبانة سنوي شامل تغيير الثنمعات والفلاتر وسائل الترسيب \\
\hline 6 & جنيه /ساعة & 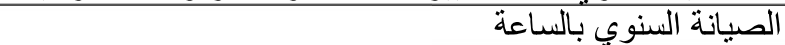 \\
\hline 6 & جنيه /ساعة & إجمالي التكاليف المتغيرة \\
\hline \multirow[t]{2}{*}{12.718} & جنيه /ساعة & التكلفة الإجمالية لكل ساعة تتغيل \\
\hline & & أثالثاً: التكلفة لكل متز م³ ماء \\
\hline 10.000 & متر مكعب & تصرف وحدة المعالجة أو التحلية \\
\hline 1.272 & جنيه /متر مكعب & تكلفة تحلية أو معالجة المتر المكب من الماء \\
\hline
\end{tabular}

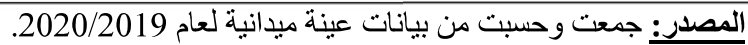

جنيه/م3 باستخدام مضخات كهربائية مع دعم الكهرباء، في

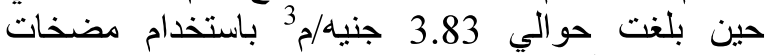

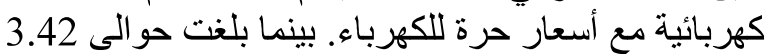

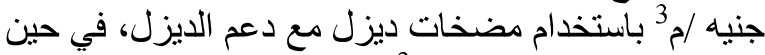

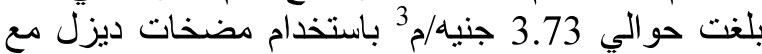

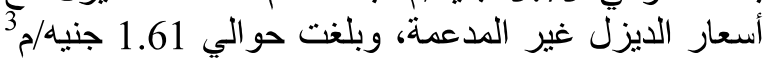
باستخدام مضخات تعمل بالطاقة الثمسية.

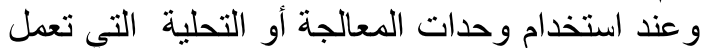

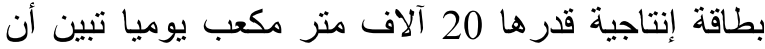

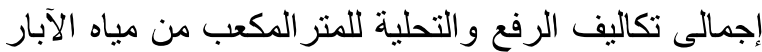

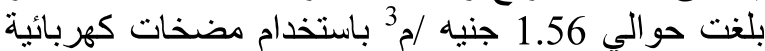

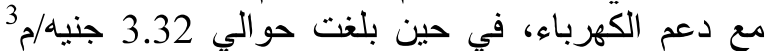
باستخدام مضخات كهربائية مع أسعار حرة للكهرباء دئ بيناء بينما

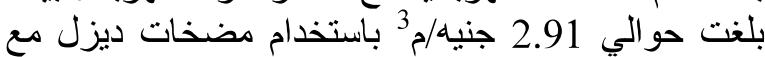

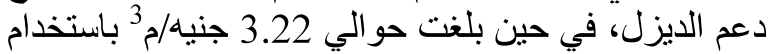

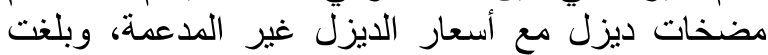
حوالي 1.11 جنيه/م33 باستخدام مضخات تعمل بالطاقة الطية

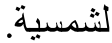

بمقارنة تكلفة الرفع والتحلية باستخدام المضخات

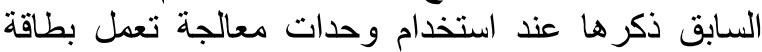

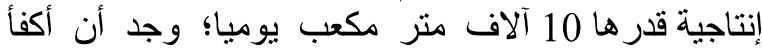
المضخات كانت مضخات الطاقة الثمسية حيث بلغت بلت تكلفة الرفع حوالى 1.6 جنيه/ساعة، يليها المضخات الكهات الكرباتئية

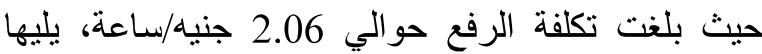
مضخات الديزل حيث بلغت تكلفة الرفع حوالي 3.42
2.1.3.5.تقدير تكاليف معالجة أو تحلية المتر المكب

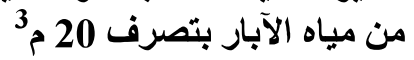

يبين جدول (6) تكاليف تحلية متر مكعب مياه مئمباه الآبار

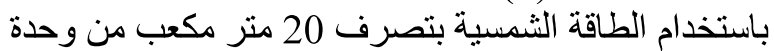

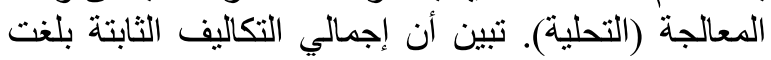

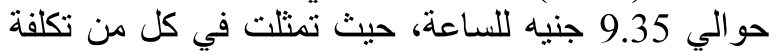

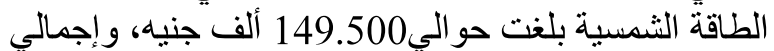

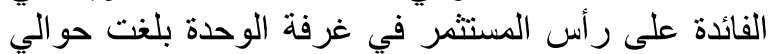

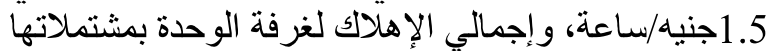

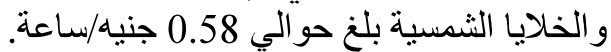

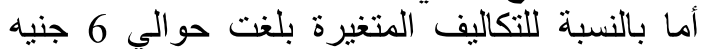
للساعة، تمثلت في كل من تكاليف الإصلاح و الصيانة الصيانة بلغت

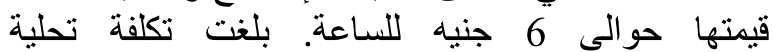

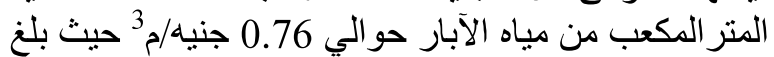

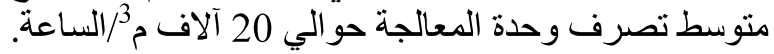

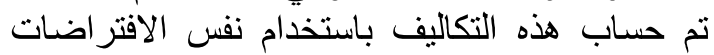

السابق الإشارة إليها في جدول (5).

3.1.3.5.إجمالي تكاليف رفع وتحلية مياه الآبار وفقا لنظم رفع مختلفة

يوضح جدول (7) مقارنة لتكاليف رفع وتحلية

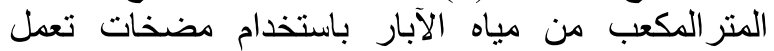
بالكهرباء والديزل والطاقة الثمسية. تبين عند التينة التخدام وحدات المعالجة أو التحلية التي تعمل بطاقة إنتاجية قدرها

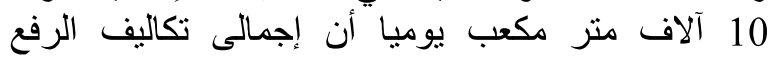
والتحلية للمتر المكعب من مياه الآبار بلغت حوالي 2.06 
جدول ( 6): تكاليف تحلية أو معالجة متر مكعب من مياه الآبار بطاقة إنتاجية قدرها 20 متر مكب يومياً.

\begin{tabular}{|c|c|c|}
\hline 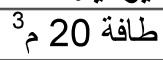 & 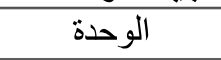 & البنود \\
\hline & & أو لا: التكاليف الثابتة \\
\hline 149500 & جنيه & تكلفة خلايا الطاقة الثمسية ومستلزماتها المختلفة \\
\hline 25 & سنة & متوسط العُمر الإنتاجى للَّحدة بالسنة \\
\hline 300 & يوم & متوسط عدد ايام تثنغيل سنويا \\
\hline 10 & 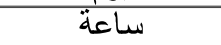 & منوسط عدد ساعات التشغيل اليومي \\
\hline 75000 & ساعة & العمر الإنتاجى للوحدة بالساعة \\
\hline 1.993 & جنيه /ساعة & متوسط إهلاك الخلايا الثمسية ومستلز ماتها \\
\hline 44000 & جنيه & تكلفة إنشاء غرفة الوحدة \\
\hline 0.587 & جنيه /ساعة & إهلاك غرفة الوحدة \\
\hline 0.105 & $\%$ & معدل الفائدة \\
\hline 15697.5 & جنيه & الفائدة على راس المال المستّمر في الخلايا النُمسية \\
\hline 5.2325 & جنيه /ساعة & الفائدة على راس المال المستُّمر في الخلايا التُّمسية بالساعة \\
\hline 4620 & جنيه & الفائدة على رأس المال المستثمر في غرفة الوحدة \\
\hline 1.54 & جنيه /ساعة & الفائدة على رأس المال المستّر في غرفة الوحدة بالساعة \\
\hline 9.353 & جنيه /ساعة & إجمالي التكاليف الثنابتة للساعة \\
\hline & & ثانيا: التكاليف المتغيرة \\
\hline 18000 & جنيه & عقد صيانة سنوي شامل تغيير النثمعات والفلاتر وسائل الترسيب \\
\hline 6 & جنيه /ساعة & الصيانة السنوي بالساعة \\
\hline 6 & جنيه /ساعة & إجمالي التكاليف المتغيرة \\
\hline 15.353 & جنيه /ساعة & ألتكلفة الإجمالية لكل ساعة تثنغيل \\
\hline & & أثالثاً: التكلفة لكل متر م ماء \\
\hline 20.000 & متز مكعب & تصرف وحدة المعالجة أو التحلية \\
\hline 0.768 & جنيه /متر مكعب & تكلفة تحلية أو معالجة للمتر المكعب من الماء \\
\hline
\end{tabular}

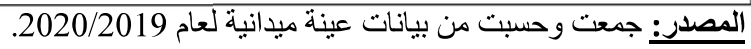

جدول (7): تكاليف رفع وتحلية او معالجة متر مكعب من مياة الابار وفقا لنظم رفع مختلفة.

\begin{tabular}{|c|c|c|c|}
\hline وحدة 20 م & وحدة 10 م³ & 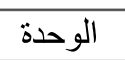 & البنود \\
\hline 0.796 & 0.796 & 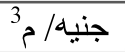 & تكاليف رفع متر مكعب مياه من الآبار باستخدام مضخات كهربائية مع دعم الكهرباء \\
\hline 2.559 & & 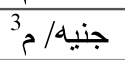 & تكاليف رفع متر مكعب مياه من الآبار باستخدام مضخات كهربائية مع أسعار حرة للكهرباء \\
\hline 2.152 & 2.152 & جنيه/م3 & تكاليف رفع متر مكعب مياه من الآبار باستخدام مضخات ديزل مع دعم الديزل \\
\hline 2.460 & 2.460 & 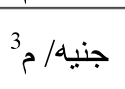 & تلكاليف رفع متر مكعب مياه من الآبار باستخدام مضخات ديزل مع أسعار غير مدعومة \\
\hline 0.344 & & 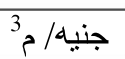 & تكاليف رفع متر مكعب مياه من الآبار باستخدام مضخات بالطاقة الثشمية \\
\hline 1.564 & 2.068 & جنيه/م3 & تكاليف رفع وتحلية متر مكعب مياه من الآبار باستخدام مضخات كهربائية مع دعم الكهرباء \\
\hline 3.326 & 3.831 & 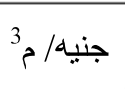 & لككاليف رفع وتحلية متر مكعب مياه من الآبار باستخدام مضخات كهربائية مع أسعار حرة \\
\hline 2.919 & & 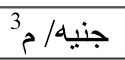 & تكاليف رفع وتحلية متر مكعب مباه من الآبار باستخدام مضخات ديزل مع دعم الديزل \\
\hline 3.228 & 3.732 & 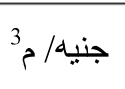 & تكاليف رفع وتحلية متر مكعب مياه من الآبار باستخدام مضخات ديزل مع أسعار غير \\
\hline 1.112 & 1.616 & جنيه/ م33 & تكاليف رفع وتحلية متر مكعب ه \\
\hline
\end{tabular}

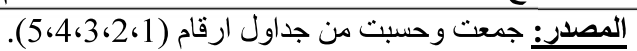

الكهربائية حيث بلغت تكلفة الرفع حوالي 1.56

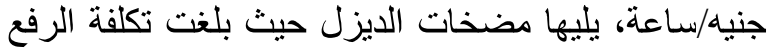

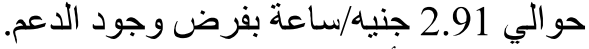

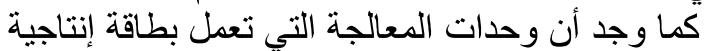

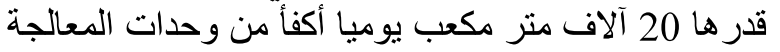

جنيه/ساعة بفرض وجود الدعم. أما بمقارنة تكلفة الرفع و والتحلية باستخدام المضخات

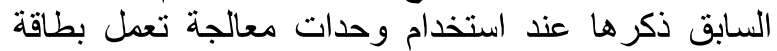

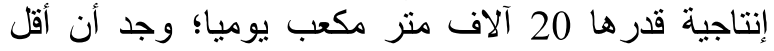

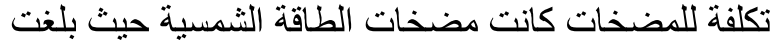
تكلفة الرفع حوالى 1.1 جنيه/ساعة، يليها المضخات 
المنزلي أقل من تكلفة مياه الثرب التي تقدمها مشاريع

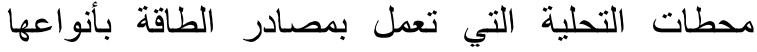

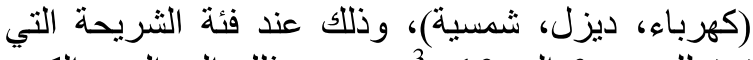

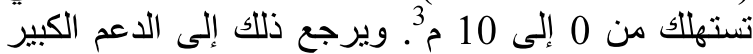
على مياه الثرب والذي تقدمه الحكومة للفئات الفقيرة

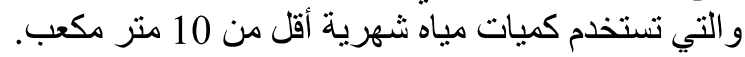
2.4.5. تكلفة مياه الشرب التي تقدمها الحكومة للاستهلاك

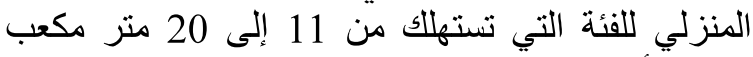
شهريا أكبر من تكلفة مياه الثرب التي تلتي يتم معالجتها

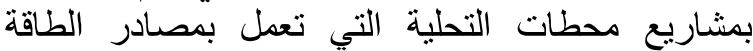

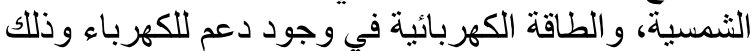

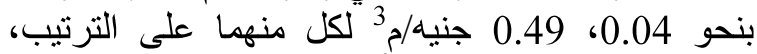
وذللك عند فئة 11 إلى 20 م. 3. 3.4.5 تكلفة مياه الثرب التي تقدمها الحكومة للاستهلاك

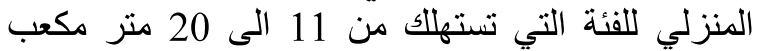
شهريا" أقل من تكلفة مياه الثرب التئي التي يتم معالجتها بمشاريع محطات التحلية التي تعمل بالطيات التئة الكهربائية

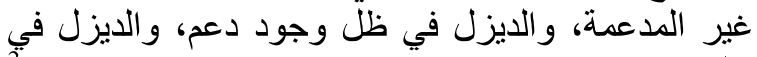

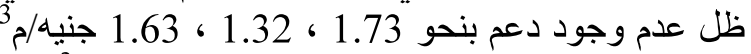

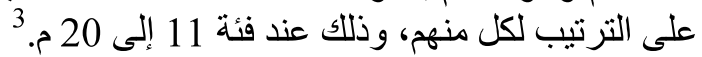

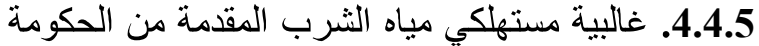
يلجأون إلى تركيب الفلاتر المنزلية لمعالجة هذه المياه حتى تكون أكثر أمانا لاستخداماتهم المختلفة الفئة 5.4.5 ـ تكلفة المياه الناتجة عن مشاريع لأندانئ محطات التحلية

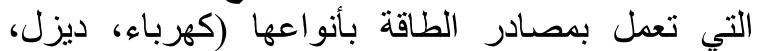
شمسية) أقل من تكلفة المياه التي تطرحها شركات التركات المياه

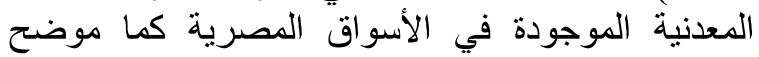

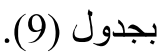

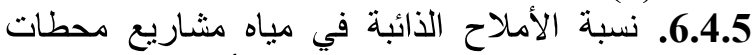

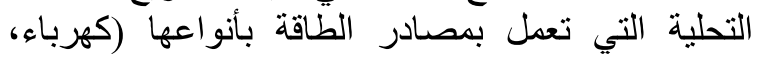

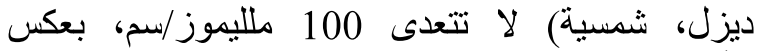
الأملاح الذائبة الموجودة بالمياه المعدنية التي تطرحها

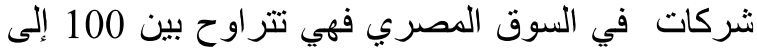

270 ملجم/تلتر كما موضح بجدول (9).
التي تعمل بطاقة إنتاجية قدر ها 10 آلاف متر مكعب يوميا،

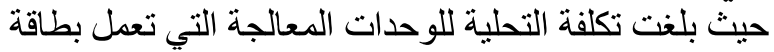

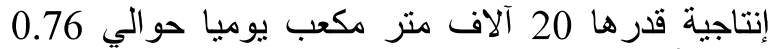
جنيه/م3، بينما للوحدات المعالجة التافي التي تعمل بطاقة إنتاجية قدر ها 10 آلاف منر مكعب يوميا بل بلغت تكلفة التحلية حو الي بلي

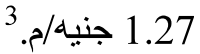

4.5 ـ تحليل مقارن بين آداء مقدمي خدمات مياه الشرب

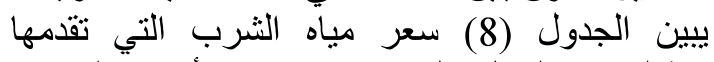

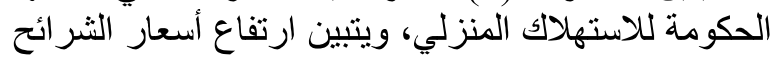

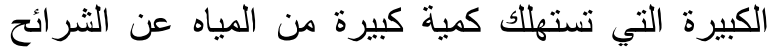

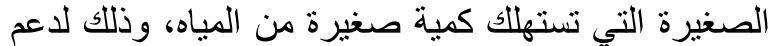

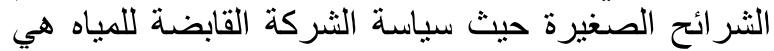

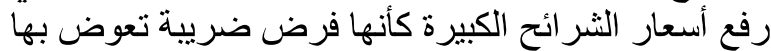

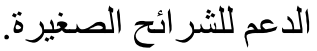

جدول(8): تعريفة مياه الشرب المخصصة لأنشطة الاستهلاك المنزلي للعام المالي 2020/2019.

\begin{tabular}{|c|c|}
\hline التعريفة (جنيه/م³) & تقسيم الثر ائح* \\
\hline 0.65 & من 10 : 0 مج \\
\hline 1.60 & من 20: 11 مج \\
\hline 2.25 & من 30 : 21 م م) \\
\hline 2.75 & من 40 : 31 ج \\
\hline 3.15 & اكثتر من 40 مُ3 \\
\hline
\end{tabular}
.2020/2019

يوضح الجدول (8) أن فئة الثريحة التي تستهلك من

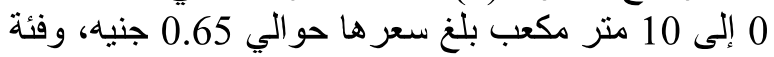

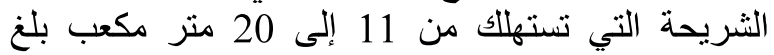

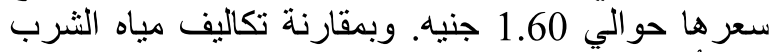

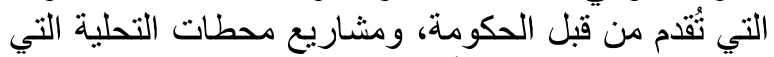

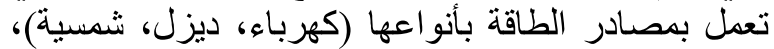
وشركات المياه المعدنية الموجودة في الأسواق المينائ الدصرية

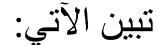
1.4.5. تكلفة مياه الثرب التي تقدمها الحكومة للاستهلاك

جدول (9): كمية الأملاح الذائبة للمياه المعدنية التي تطرحها الثركات بالأسواق المصرية وأسعارها.

\begin{tabular}{|c|c|c|c|}
\hline السعر (جنيه/ק') & السعر (جنيه/لتر) & الأملاح الذائبة (ملجم/ لتر) & النوع \\
\hline 330 & 1.83 & 153 & دساني \\
\hline 1100 & 2.6 & 124 & نسلة \\
\hline 1430 & 2.93 & 176 & بركة \\
\hline 1000 & 2.5 & 189 & حياة \\
\hline 330 & 1.83 & 180 & فيرا \\
\hline 870 & 2.37 & 262 & ايزيس \\
\hline 930 & 2.43 & 268 & 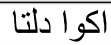 \\
\hline 470 & 1.97 & 130 & اكو افينا \\
\hline
\end{tabular}

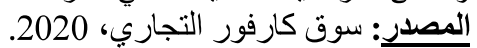


• سولونيد فالف محبس كهربائى للتحكم في دخول

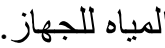
• كنترول تحكم لحماية الجهاز من الفلو والأمبير

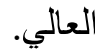

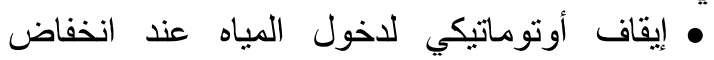
الضغط المغذي للجهاز. • ش شاسيه حامل لكل مكونات الوحدة. • عدد 2 فلو ميتر لقياس كمية المياه الناتجة وآخر للمياه المنصر فة فئ. • محبس للتحكم في كمية المياة المنتجة والضغوط

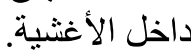
• لوحة كهرباء وتحكم في الوحدة.

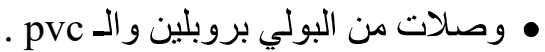
• وحدة حقن لمانع الترسيب إيطالي طاقتها 5 لتر في الساعة.

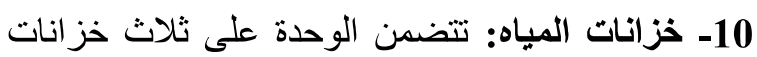

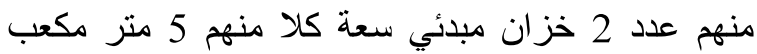
وخزان نهائي طاقته التخزينية 3 متر مكعب لتخزين المياه المنتجة. 11- غرفة المحطة: يتم إنثاء غرفة ذات أبعاد4 مثر

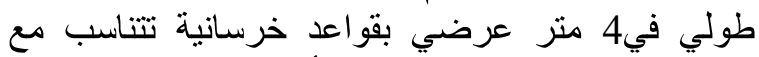
الإنثاءات ويتم استخدام الطوب الأسمنتي في الحوائط ويتم

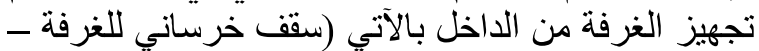

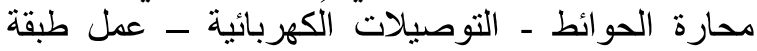
خرسانية أرضية لكي تتناسب مع الأحمال - سير اميك الكئل الأرضية - توصيل مصدية أرضية المياه من البئر حتى داخل

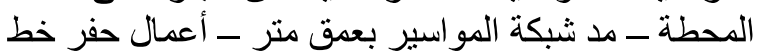

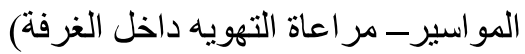
12- تكاليف توريد المحطة: حوالي (95,000) جنيها فقط لئ

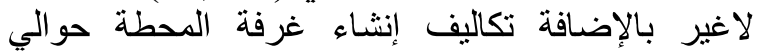

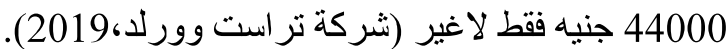
2) المعاملات الفنية لوحدة معالجة أو تحلية المياه بطاقة إنتاجية قدرها 20 متر مكعب يومياً:

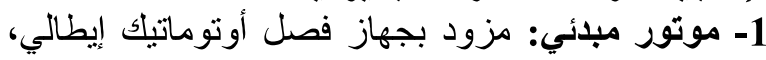

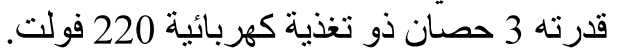

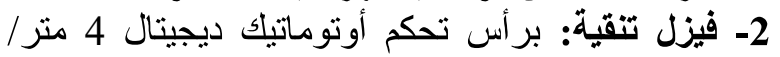

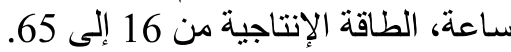

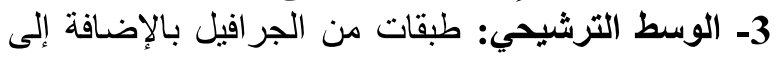
طبقات من الحصاً الناعم و الخشن لإز الة الرئ الرواسب.

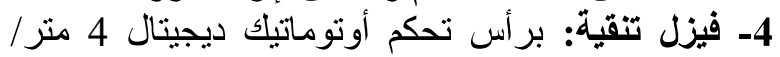

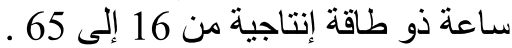

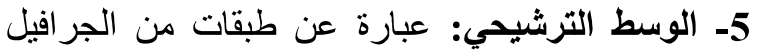

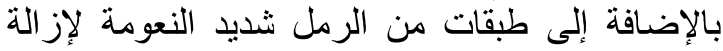
أكاسيد الحديد.

6- فيزل تنقية: براس تحكم أوتوماتيك ديجيتال قدرته 4 ألى 4 ألى

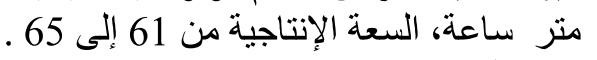
7- الوسط الترشيحي: عبارة عن طبقات من الإنتافئ الجرافيل

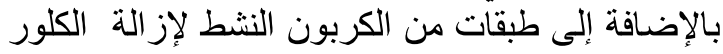
و اللون والطعم و الر ائحة غير المن المربون اللية.

\section{التوصيات}

في ضوء النتائج السابقة يوصي البحث بما يلي:

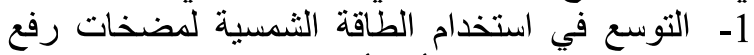
وتحلية المياه، حيث أنها أقل تكلفة عن طاقة الكهرباء الكياء والديزل في ظل الإرتفاع المستمر لتكلفة الكهرباء

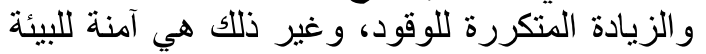

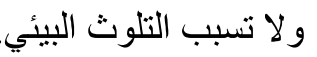
2- مساندة الحكومة لمشاريع تحلية المياه، بتقديم الدعم لمصادر الطاقة المختلفة لها. 3- الإتجاه إلى مشاريع رفع وتحلية أو معالجة المياه من المناه الآبار ، حيث أنها أقل تكلفة مقارنة بالمياه المعان المدنية التي

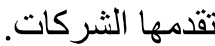

\section{الملحق}

المعاملات الفنية لوحدات المعالجة موضع الداراسة:

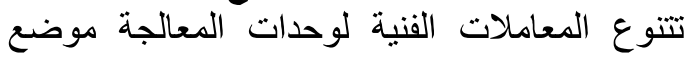

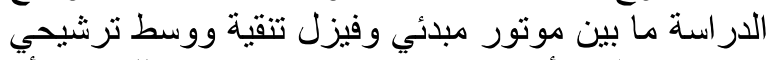

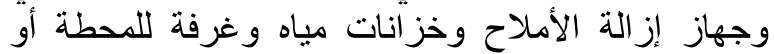

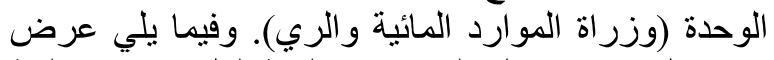

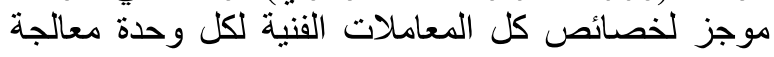
من الوحدات موضع الدر اسة.

1) المعاملات الفنية لوحدة معالجة الوراتة أو تحلية المياه بطاقة إنتاجية قدرها 10 متر مكعب يومياً:

1- موتور مبائي: مزود بجهاز فئرئ فيل أوتوماتيك إيطالي قدرته 3 حصان ميكانيكي، و التغذية الكهربائية 220 فولت فئيك

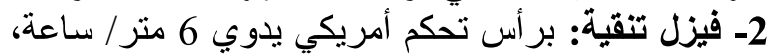

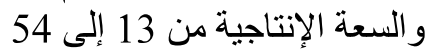

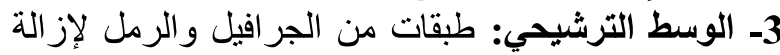

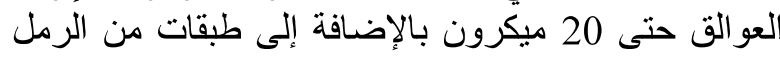

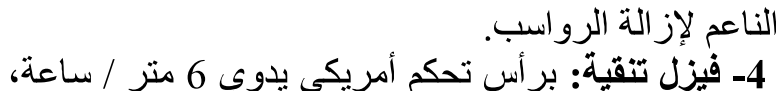

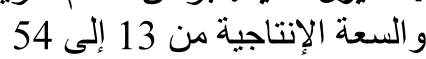
5- الوسط الترشيحى: طبقات من الجر افيل بالإضافة إلى لـ الإنى

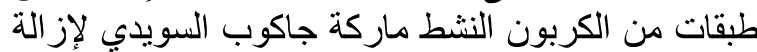
الكلور و اللون و الطعم و الر ائحة.

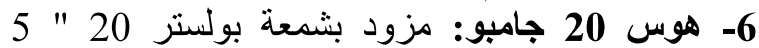

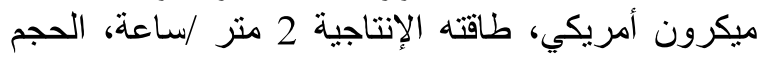

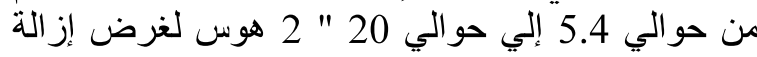

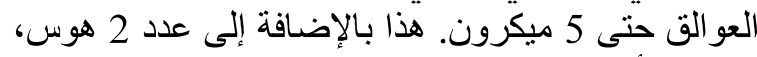

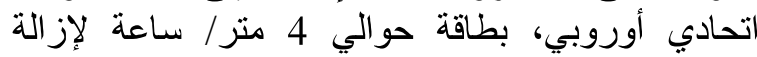

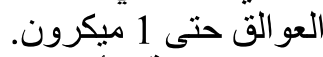

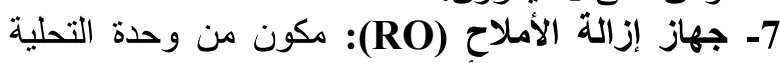
داخل غشاء استانلس أمريكية الصنع ذاح ذات طاتل طاقة إنتاجية حوالي 3000 جالون يوميا وذات حجم

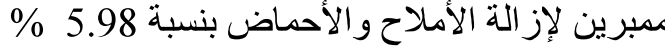
8- موتور الضغط العالي: إيطالي قدرته الميكانيكية 3

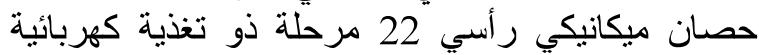

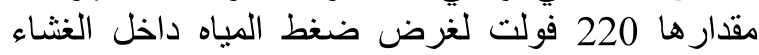
الأسموزي (وحده التحلية) بقوة ضغط فئ مقدار ها ضات 10 بار. 9- جهاز إزالة الأملاح مزود بالمستلزمات التهات التالية: 
بالإضافة إلى عدد 2 نانك نهائي لتخزين المياه المنتجة، 13 مالج لتخزين المياه سعة التانلك 5 مثر. 13- تكاليف توريد المحطة: حوالي (149,500) جنيه بالإضافة تكاليف إنشاء غرفة المحطة حو الي

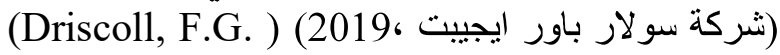

.1986

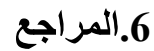

$$
\begin{aligned}
& \text { الإنترنت، موقع وزارة الموارد المائية والري } \\
& \text { WWw.mwri.gov.eg }
\end{aligned}
$$

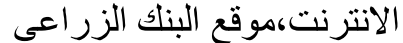

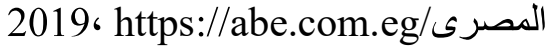

الثركة القابضة لياه الثرب والصرف الصحي، .2020/2019

إلهام محمد عبد العظيم علي: دراسة اقتصادية لنظم الري

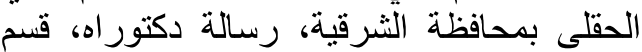

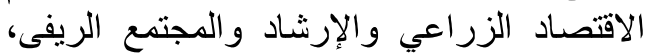
كلية الزراعة، جامعة قناة السويس، الإسماعيلية ، مصر 2019. النصر للطاقة الشمسية، مقال متاح على موقع الانترنت (2019) ،https://nasrsolar.com سوق كارفور التجاري، مدينة نصر ، (2020). شركة تراست ورولد تكنولوجيا معالجة مياه الثربه

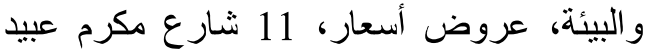
بجوار محجوب مدينة نصر القاهرة،

شركة سولار باور ايجيبت، عروض أسعار، 2 أبو بكر الصديق، الدقي، الجيزة، بأل 2019.

معهد التخطيط القومي، تتمية وترشيد استخدامات الميات المياه في مصر ، سلسله قضايا التخطيط و التتمية، العدد رقية

$$
\text { 282، سبتمبر (2017). }
$$

وزارة المياه والكهرباء، مركز إنماء المملكة للتدريب و التطوير، تشغيل وصيانة محطات تنقية المياه، متاح على موقع الانترنت

https://water.ma/media/documentation2017

Driscoll F.G. (1986). Groundwater and wells. $2^{\text {nd }}$ edition, Johnson Division, St. Paul, Minnesota,USA.

Wayback Machine (2017). Sea Water Desalination, Menachem Elimelech: Sea water desalination, department of chemical and environmental engineering, yale university, clalifornia, united states of America, November (1):2017.
8- هوس 20 "جامبو: مزود بشععه بولي 20 " 5 ميكرون

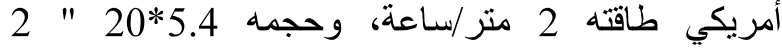

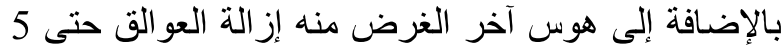

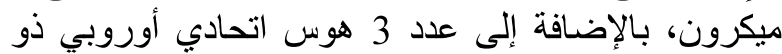
طاقة 4 منز/ / ساعة والغرض اللى منه إزالة التعو الق حتى أنى "9- جرون .

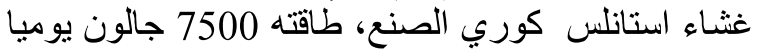

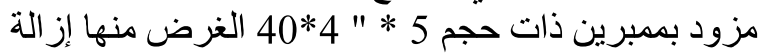
الأملاح و الأحماض بون 98.5 \%

10- موتور الضغط العالي: إيطالي قدرته 3 الأله حصان ر رأسي

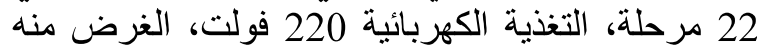
ضغط المياه داخل الغثاء الأسموزي داخل وحدة التحلية ب ضغط 10 بار.

11- جهاز إزالة الأملاح مزود بالمستلزمات التالية: سولونيد فالف محبس كهربائي للتحكم في دخول بالئل

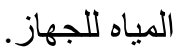
كنترول تحكم لحماية الجهاز من الفلو والأمبير • العالي.

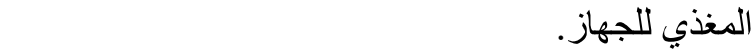
شُاسيه حامل لكل مكونات الوحده للحفاظ على العمر الافتر اضي لمكونات الوحدة.

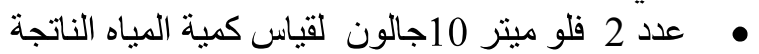
وآخر للمياه المنصرفة فئر

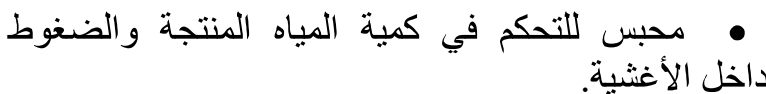
لوحة كهرباء وتحكم في الوحدة.

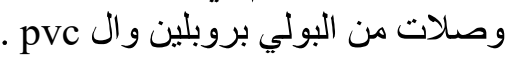
وحدة حقن لمانع الترسيب إيطالي طاقتها 5 لتر في الساعة • وحدة حقن كلور لقتل البكتيريا و التعقيم داخل الخزان المبدئي إيطالية الصنع.

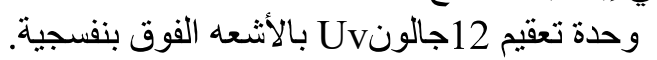

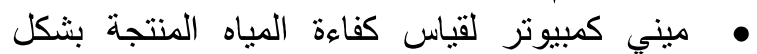

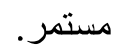
• موتور خاص بالمياه المنتجة استالس أستيل1حصان إيطالي

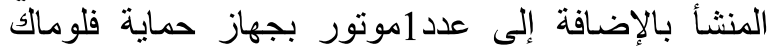
إيطالي المنشأ. جهاز قياس الأملاح.

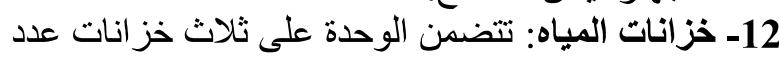

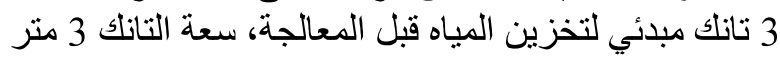

